\title{
DESENVOLVIMENTO DE REQUEIJÃO CREMOSO SEM LACTOSE
}

\section{Development of "requeijão cremoso" without lactose}

\author{
Andréia Paula Dal Castel ${ }^{*}$, Creciana Maria Endres ${ }^{l}$, \\ Andressa Barella de Freitas ${ }^{1}$, Vera Maria Rodrigues ${ }^{2}$
}

\begin{abstract}
RESUMO
A intolerância a lactose é o nome dado a uma disfunção do organismo que apresenta uma deficiência ou ausência da produção da enzima lactase ( $\beta$-galactosidase), responsável pela conversão da lactose em glicose e galactose. É comum em todas as faixas etárias e etnias, sua principal consequência é a impossibilidade de ingestão de produtos contendo lactose, como leite e seus derivados. Antecipando-se a isso, a indústria alimentícia hidrolisa a lactose a fim de obter um produto compatível aos portadores dessa doença, sem comprometer as características já encontradas em produtos sem esse tratamento. Sendo assim, o objetivo deste trabalho foi desenvolver um requeijão cremoso sem lactose. Utilizou-se leite desnatado como matéria-prima e $\beta$-galactosidase em concentrações de $0,07 \%, 0,1 \%$ e $0,2 \%$. O tempo de hidrólise foi de 90 minutos a um $\mathrm{pH}$ de 6,55 e temperatura de $40{ }^{\circ} \mathrm{C}$. A cromatografia líquida de alta eficiência demonstrou que o grau de hidrólise das formulações foi satisfatório. $\mathrm{O}$ produto desenvolvido adequou-se aos padrões estabelecidos pela legislação brasileira quanto aos limites microbiológicos e físico-químicos. A análise sensorial foi realizada com escala hedônica de 9 pontos com painel de 100 julgadores não treinados, não mostrando diferença estatística significativa entre amostras de requeijão sem lactose e tradicional. Sendo assim, a formulação contendo $0,07 \%$ de enzima $\beta$-galactosidase pode ser considerada um requeijão com baixo teor de lactose e é uma ótima alternativa para intolerantes, pois possui sabor e custo similar ao tradicional.
\end{abstract}

Palavras-chave: intolerância; hidrólise; enzima.

1 Serviço Nacional de Aprendizagem Industrial (SENAI), Departamento de Tecnologia de Alimentos, Rua Frei Bruno 201 E, Bairro Jardim América, 89803-785, Chapecó, SC, Brasil. E-mail: andreia. pdc2304@gmail.com

2 Universidade de Passo Fundo (UPF), Departamento de Tecnologia de Alimentos, Passo Fundo, RS, Brasil.

* Autor para correspondência. 


\begin{abstract}
Lactose intolerance is the name given to a dysfunction of the body, which has a deficiency or lack of production of enzyme lactase ( $\beta$-galactosidase), responsible for the conversion of lactose into glucose and galactose. It is common in all age groups and ethnicities, its main consequence is the impossibility of ingesting products containing lactose, such as milk and its derivatives. Anticipating this, the food industry hydrolyzes lactose in order to obtain a product compatible with the disease, without compromising the characteristics already found in products without this treatment. Therefore, the objective of this work was to develop a "requeijão cremoso" without lactose. Skim milk were used as the main ingredient and $\beta$-galactosidase was added in concentrations of $0.07 \%, 0.1 \%$ and $0.2 \%$, the hydrolysis time was 90 minutes at a $\mathrm{pH}$ of 6.55 and a temperature of $40{ }^{\circ} \mathrm{C}$. Analyses mode by high performance liquid chromatography showed that the degree of hydrolysis of the formulations was satisfactory. The developed product was adequate to the standards established by Brazilian legislation regarding to microbiological and physico-chemical standards. The sensorial analysis was performed with a hedonic scale of 9 points with a panel of 100 untrained judges, showing no statistically significant difference between samples of lactose-free and traditional curd. Thus, the formulation containing $0.07 \%$ of $\beta$-galactosidase enzyme can be considered a low-lactose curd, it is a good alternative for intolerants, since it has a similar taste and cost to the traditional one.
\end{abstract}

Keywords: intolerance; hydrolysis; enzyme.

\section{INTRODUÇÃO}

O leite é um produto largamente consumido no Brasil e no mundo devido a sua rica composição em nutrientes e sua extensa escala de derivados, dentre eles destacase o requeijão, um produto genuinamente brasileiro que vem ganhando força no mercado consumidor. Sua produção que era de 9,8 mil toneladas em 1992, passou para 72,1 toneladas em 2011, tornando-se um dos principais produtos produzidos pelos laticínios brasileiros (SANTOS et al.,2014; VIEIRA et al., 2014).

A lactose é um carboidrato de origem animal que está presente na dieta alimentar do homem. Quando sintetizada pelo organismo humano é hidrolisada pela enzima lactase formando glicose e galactose, sendo então absorvida pelo organismo. Os indivíduos intolerantes à lactose apresentam uma defi- ciência ou ausência na produção da enzima lactase pelo organismo, problema associados a idade e/ou etnia, podendo surgir em maior ou menor intensidade, comumente causando flatulências, diarreia e vômito no indivíduo (ALMEIDA et al., 2015; PARRA et al., 2015).

A diminuição da atividade da lactase no organismo é progressiva com o decorrer dos anos, principalmente entre crianças e adolescentes. Essa taxa também varia conforme a etnia, afetando principalmente pessoas negras e asiáticas. Na América do Sul, a prevalência de intolerância à lactose é de 65 a 75\% em adultos (TREVISAN, 2008; SANTOS et al., 2014; ARIAS et al., 2015).

Para resolver este problema, a indústria alimentícia hidrolisa a lactose antecipadamente à ingestão, gerando moléculas de glicose e galactose a partir de processos tecnológicos como a hidrólise enzimática. Segundo Faedo et al. (2013), a vantagem do método 
de hidrólise enzimática é que a reação se processa a temperatura relativamente baixa, numa faixa que pode variar de $4{ }^{\circ} \mathrm{C}$ a $40{ }^{\circ} \mathrm{C}$, sendo a temperatura ótima entre $30{ }^{\circ} \mathrm{C} \mathrm{a} 40{ }^{\circ} \mathrm{C}$.

Quando a lactose é hidrolisada no intestino delgado pela enzima lactase, ela é convertida em glicose e galactose, que são absorvidos pela corrente sanguínea, porém, quando isso não ocorre, acontece o que chamamos de intolerância a lactose. Sendo assim, a lactose permanece no intestino delgado onde sofre uma fermentação bacteriana que gera ácido láctico, dióxido de carbono e gás hidrogênio, ocasionando diarréia, inchaço, flatulência e cólica. Aproximadamente 80\% da população mundial possuem essa intolerância, sendo $25 \%$ de brasileiros (FISCHER, 2010; BRAGA, 2012; ENDRES et al., 2016).

Segundo a Portaria ${ }^{\circ} 29$, de 13 de janeiro de 1998, que normatiza o Regulamento Técnico referente a Alimentos para Fins Especiais, fica claro que alimentos especialmente formulados para atender às necessidades de portadores de intolerância à ingestão de dissacarídeos e/ou portadores de erros inatos do metabolismo de carboidratos, podem conter no máximo $0,5 \mathrm{~g}$ do nutriente em referência, por $100 \mathrm{~g}$ ou $100 \mathrm{~mL}$ do produto final (ANVISA, 1998). Desta forma, para que os produtos lácteos sejam considerados deslactosados, estes devem apresentar residual de lactose menor que $0,5 \mathrm{~g} / 100 \mathrm{~g}$.

O objetivo deste estudo foi desenvolver um requeijão cremoso sem lactose definindo a concentração de enzima a ser utilizada em seu processo, além de avaliar suas características físico-químicas, microbiológicas e sensoriais.

\section{MATERIAL E MÉTODOS}

O processo de fabricação do requeijão, bem como as análises microbiológicas e físico-químicas foram realizadas em um laticínio localizado na região oeste de Santa Catarina. Já as análises de lactose e
Staphylococcus Coagulase Positiva foram realizadas em laboratórios credenciados pelo Ministério da Agricultura, Pecuária e Abastecimento.

Foram preparadas quatro formulações distintas para o estudo, designadas como T1, T2, T3 e T4, sendo que em todas foi utilizado leite desnatado pasteurizado contendo $0 \%$ de gordura.Cada formulação recebeu diferentes concentrações de enzima $\beta$-galactosidase, exceto a formulação T4 ou controle, sendo essa a formulação padrão. Na Tabela 1 estão descritas as concentrações de $\beta$-galactosidase utilizadas em cada formulação.

Tabela 1 - Concentração de enzima $\beta$-galactosidase incorporadas em cada formulação

\begin{tabular}{cc}
\hline Formulação & $\% \beta$-galactosidase \\
\hline T1 & $0,07 \%$ \\
T2 & $0,1 \%$ \\
T3 & $0,2 \%$ \\
T4 & $0 \%$ \\
\hline
\end{tabular}

O teste com várias concentrações de enzima foi realizado para verificar qual a concentração mínima pode ser utilizada no processo, desde que apresente teor residual aceitável por indivíduos intolerantes à lactose. A enzima utilizada foi a lactase $\beta$-galactosidase obtida do fungo Kluyveromyces lactis, nome comercial Maxilact ${ }^{\circledR}$ LGX-5000, fabricada por DSM Food Specialties France, importada pela Global Food, São Paulo, Brasil. Segundo o fabricante da enzima, cada grama do produto contém 5000 unidades de lactose neutra (Neutral Lactose Units NLU), conforme descrito no boletim técnico da enzima. Uma NLU é definida como a quantidade de enzima que libera $1,0 \mu \mathrm{mol}$ de o-nitrofenol por minuto, sob as condições do teste. De acordo com Carminatti (2001), a quantidade de proteínas é da ordem de $54,9 \mathrm{mg} / \mathrm{mL}$. 
Para todas as formulações foram utilizados os mesmos indicadores para a hidrólise, o leite foi aquecido a $40{ }^{\circ} \mathrm{C}$, após adicionou-se a concentração da enzima e manteve-se nesta temperatura com agitação controlada por 90 minutos para hidrólise da lactose. A definição da temperatura e tempo foram baseados no estudo de Faedo et al. (2013) e nas indicações do fabricante.

Após o período de hidrólise de $90 \mathrm{mi}$ nutos, procedeu-se a fabricação da massa com a acidificação direta do leite (houve a coagulação do leite com o auxílio de ácido lático, com dessoragem e lavagem da massa posteriormente). A massa obtida foi mantida sob refrigeração em câmara fria a $10^{\circ} \mathrm{C}$. O teor de lactose residual foi determinado somente no produto final por cromatografia líquida de alta eficiência (CLAE).

O processo de fabricação do requeijão cremoso foi realizado conforme apresentado na Figura 1. A fusão ocorreu a vácuo, em panela de Geiger com adição de gordura láctea e leite desnatado a $0 \%$ de gordura, sem lactose.

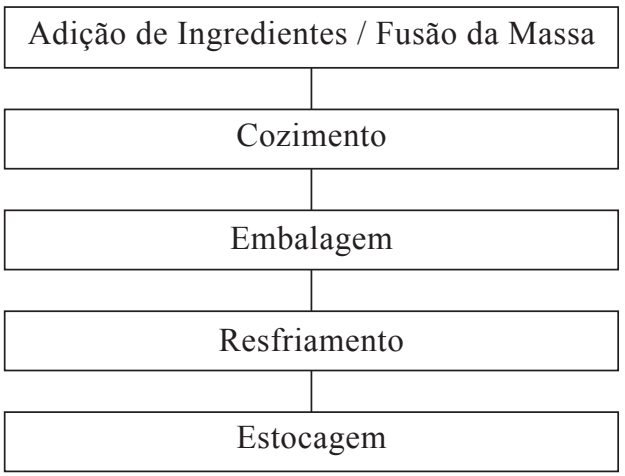

Fonte: Modificado de Van Dender (2006).

Figura 1 - Fluxograma do processo de fabricação de requeijão cremoso

As análises físico-químicas foram realizadas nos dias 1, 15, 30, 45, 60 e 75 de armazenamento, sendo que a análise de lactose foi realizada somente no $1^{\circ}$ dia de arma- zenamento no produto final. As análises de gordura, umidade, gordura no extrato seco e $\mathrm{pH}$ foram realizadas conforme descrito na Instrução Normativa $n^{0} 68$ de 2006 (BRASIL, 2006). Os teores de lactose da amostra padrão e de lactose residual nas amostras finais foram determinadas pelo método de carboidratos por cromatografia líquida de alta eficiência (CLAE).

As análises microbiológicas foram realizadas a partir de testes presuntivos e confirmatórios para coliformes totais $\left(30^{\circ} \mathrm{C}\right)$, termotolerantes $\left(45^{\circ} \mathrm{C}\right)$ e contagem de Staphylococcus Coagulase Positiva, seguindo a metodologia descrita pela Instrução Normativa $n^{\circ} 62$ de 2003, em triplicata (BRASIL, 2003).

A análise sensorial foi aplicada com painel de 100 julgadores não treinados, com faixa etária entre 18 e 72 anos. Utilizou-se o método de escala hedônica de 9 pontos, conforme Figura 2, a fim de avaliar a aceitabilidade dos atributos cor, odor, sabor, textura e avaliação global. Houve a comparação com o produto tradicional e buscou-se avaliar a intenção de compra por meio de escala hedônica de cinco pontos.

Foram avaliadas duas amostras: uma amostra padrão e uma sem lactose, definida pelo autor como a que estava em melhor condição de hidrólise e também que atendeu a legislação. Como a análise foi realizada com apenas duas amostras, os resultados obtidos foram tratados estatisticamente através do teste ANOVA. O projeto foi submetido e aceito pelo comitê de ética da Universidade de Passo Fundo - RS, obtendo parecer número: 1.121.492.

\section{RESULTADOS E DISCUSSÃO}

O teor de lipídios variou de 27,25\% a $30 \%$ durante o armazenamento por 75 dias, conforme observado na Tabela 2. Devido à grande quantidade de gordura láctea utilizada na formulação, os testes desenvolvidos ficaram com teores de lipídios superiores aos 


\section{ANALISE SENSORIAL - "Requejaão Cremoso sem lactose"}

Provador:

Idade:

Você está recebendo três amostras de Requeijẫo sem lactose.

1) Deguste as mesmas e dê uma nota para cada atributo, conforme a escala abaixo:

\begin{tabular}{||c|c|c|c|c|c|c|c|c|c|}
\hline Nota & 9 & 8 & 7 & 6 & 5 & 4 & 3 & 2 & 1 \\
\hline Significado & $\begin{array}{l}\text { Gostei } \\
\text { muitisgimo }\end{array}$ & $\begin{array}{l}\text { Gostei } \\
\text { muito }\end{array}$ & $\begin{array}{l}\text { Gostei } \\
\text { moderadamente }\end{array}$ & $\begin{array}{l}\text { Gostei } \\
\text { ligeiramente }\end{array}$ & $\begin{array}{l}\text { Nem } \\
\text { gostei / } \\
\text { nem } \\
\text { desgostai }\end{array}$ & $\begin{array}{l}\text { Desgostei } \\
\text { ligeiramente }\end{array}$ & $\begin{array}{l}\text { Deggostei } \\
\text { moderadamente }\end{array}$ & $\begin{array}{l}\text { Deggostei } \\
\text { muito }\end{array}$ & $\begin{array}{l}\text { Desgostei } \\
\text { muitisgimo }\end{array}$ \\
\hline
\end{tabular}

\begin{tabular}{|c|c|c|c|c|c|}
\hline Amostra & Cor & Odor & Sabor & Textura & Avaliação global \\
\hline 278 & & & & & \\
\hline 156 & & & & & \\
\hline
\end{tabular}

2) Você compraria esse produto? Responda atribuindo uma nota conforme a escala abaixo:

\begin{tabular}{|c|c|c|c|c|c|}
\hline Nota & $\mathbf{5}$ & $\mathbf{4}$ & $\mathbf{3}$ & $\mathbf{2}$ & 1 \\
\hline Significado & $\begin{array}{c}\text { Cartamente } \\
\text { compraria }\end{array}$ & $\begin{array}{c}\text { Pogsivelmente } \\
\text { compraria }\end{array}$ & $\begin{array}{c}\text { Talvez } \\
\text { compraria }\end{array}$ & $\begin{array}{c}\text { Possivelmente } \\
\text { não compraria }\end{array}$ & $\begin{array}{c}\text { Certamente ñ̃o } \\
\text { comprania }\end{array}$ \\
\hline
\end{tabular}

\begin{tabular}{|c|c|}
\hline Amostra & $\begin{array}{c}\text { Intenção de } \\
\text { compra }\end{array}$ \\
\hline 278 & \\
\hline 156 & \\
\hline
\end{tabular}

Observações:

Figura 2 - Formulário de avaliação sensorial

encontrados na literatura. Drunkler (2009) desenvolveu um requeijão cremoso simbiótico onde os valores de lipídios variaram de $20,83 \%$ a $22,67 \%$ e Matanna (2011) encontrou um teor de lipídios variando de 20,26\% a $24,52 \%$ em suas formulações de requeijão com baixo teor de lactose.

A portaria que rege este produto, Portaria no 359 de 1997 (BRASIL, 1997), não estabelece padrões específicos para lipídios, no entanto, ele é extremamente necessário para o cálculo de gordura no extrato seco (GES), solicitado por essa portaria. Apesar dos valores encontrados para lipídios terem sido superiores aos encontrados na literatura, o teor de GES dos requeijões desenvolvidos encontrou-se dentro dos padrões estabelecidos por lei (BRASIL, 1997) que preconiza um valor mínimo de $50 \%$ de GES no produto final e, conforme a Tabela 2, os valores de GES obtidos nos requeijões desenvolvidos ficaram entre $66,21 \%$ e $77,87 \%$.

Os valores de $\mathrm{pH}$ das formulações variaram de 5,21 a 5,96 no decorrer dos 75 dias de armazenamento, como pode ser observado na Tabela 2. Valores de $\mathrm{pH}$ em requeijões estão relacionados com a vida útil do produto devido a sua relação com o controle microbiológico do mesmo, além de poder afetar as características reológicas e sensoriais do produto final. Percebe-se que houve uma diminuição do $\mathrm{pH}$ no decorrer do armazenamento devido a diversos fatores que podem ocorrer durante esse armazenamento, como a diminuição da umidade, a hidrólise de polifosfatos e as interações entre proteínas que influenciam o equilíbrio iônico (VAN DENDER, 2006). 
Tabela 2 - Análises físico químicas ao longo do armazenamento*

\begin{tabular}{ccccc}
\hline & Teor de Lipídios & $\begin{array}{c}\text { Gordura no } \\
\text { extrato seco }\end{array}$ & $\mathrm{pH}$ & Umidade \\
\hline T1 $(\%)$ & $27,25 \pm 0,88$ & $67,79 \pm 2,73$ & $5,60 \pm 0,08$ & $59,79 \pm 0,82$ \\
T2 $(\%)$ & $29,50 \pm 0,83$ & $77,87 \pm 2,33$ & $5,21 \pm 0,26$ & $61,79 \pm 0,29$ \\
T3 $(\%)$ & $28,58 \pm 0,91$ & $66,21 \pm 4,17$ & $5,41 \pm 0,14$ & $56,15 \pm 0,41$ \\
Controle $(\%)$ & $30,00 \pm 0,00$ & $68,67 \pm 1,08$ & $5,96 \pm 0,15$ & $56,31 \pm 0,68$ \\
\hline
\end{tabular}

*Os resultados apresentados na tabela são compostos por média e desvio padrão.

Observa-se na literatura que os valores de $\mathrm{pH}$ de queijo fundido oscilam na faixa de 5,4 a 6,2. Quando o pH for abaixo de 5,4 a estrutura do queijo é prejudicada e tende a uma textura granulosa. Com o $\mathrm{pH}$ acima de 6,2 , a vida útil do queijo pode ser reduzida com possíveis alterações no seu sabor e estrutura. Queijos na faixa de $\mathrm{pH}$ 5,5 a 5,7 adquirirem consistência sólida e valores acima de 5,7 tornam-se mais pastosos (BOSI, 2008).

$\mathrm{O}$ teste $\mathrm{T} 1$ e a formulação controle estavam aptos para consumo até o final do armazenamento, ou seja, no $75^{\circ}$ dia, contendo um $\mathrm{pH}$ de 5,52 e 5,75, respectivamente. O T2 e T3 apresentaram vida útil de 30 dias, possuindo um $\mathrm{pH}$ final de 5,41 e 5,57, respectivamente. Conforme apresentado na Tabela 2, os resultados obtidos são similares aos encontrados por Bosi (2008) ao desenvolver requeijões light e sem adição de gordura enriquecidos com fibra alimentar, com valores de $\mathrm{pH}$ entre 5,77 e 5,91.

Quanto à análise de umidade, a Portaria 359 de Identidade e Qualidade do Requeijão (BRASIL, 1997) estabelece um limite máximo de $65 \%$ para o requeijão cremoso. O teor de umidade dos testes elaborados oscilou de $56,15 \%$ a $61,79 \%$ durante seus 75 dias de armazenamento, conforme descrito na Tabela 2, estando todos de acordo com a legislação. Valores similares ao do presente estudo foram encontrados por Matanna (2011) ao desenvolver requeijões com baixo teor de lactose, em que os teores de umidade variaram de $58,92 \%$ a $62,9 \%$ e semelhantes também aos encontrados por Drunkler (2009), ao desenvolver uma formulação para requeijão cremoso simbiótico, onde encontrou valores entre $58,48 \%$ a $65,72 \%$.

As análises de lactose realizadas por cromatografia líquida de alta eficiência (CLAE) apresentaram resultados satisfatórios em todas as formulações de requeijão sem lactose, demonstrando que a hidrólise da lactose foi eficaz. Conforme apresenta a Tabela 3 , todas as formulações de requeijão com teor reduzido de lactose apresentaram teor abaixo de $0,20 \%$, podendo ser consumido por pessoas com restrições a este carboidrato. A Portaria $\mathrm{n}^{\circ} 29$ (ANVISA, 1998) determina que $0,5 \%$ é considerado um nível seguro de lactose para a ingestão por pessoas com intolerância a este carboidrato.

Tabela 3 - Teor de lactose residual no produto final

\begin{tabular}{cc}
\hline Teste & Lactose $\mathrm{g} / 100 \mathrm{~g}$ \\
\hline T1 & ND $<0,20$ \\
T2 & ND $<0,20$ \\
T3 & ND $<0,20$ \\
Controle & 0,97 \\
\hline
\end{tabular}

ND: não detectado.

Diante dos resultados, percebe-se que uma baixa quantidade de enzima como na formulação T1 $(0,07 \%)$ garante um produto 
considerado sem lactose, além de fornecer um produto de baixo custo se comparado com produtos preparados com maiores concentrações de enzima, pois a mesma possui um alto valor agregado.

Os resultados obtidos diferem dos encontrados por Matanna (2011), que utilizou concentrações altas de enzima lactase $(0,2 \%$, $0,5 \%$ e $0,8 \%$ ) em requeijão e, no entanto, encontrou resultados inferiores de hidrólise ao deste estudo, variando de $72,42 \%$ de hidrólise no tratamento de $0,2 \%$ de enzima até $95,84 \%$, no tratamento de $0,8 \%$ de enzima. Uma possível interferência é o método de quantificação utilizado pela autora Matanna (2011) que utilizou o kit de glicose Monoreagente K082 Bioclin, enquanto no presente estudo foi realizado a determinação por cromatografia, um método mais sensível para este tipo de identificação.

As análises microbiológicas também apresentaram resultados satisfatórios. Conforme apresentado na Tabela 4, não foi detectada a presença de coliformes totais, coliformes termotolerantes e Staphylococcus Coagulase Positiva nos requeijões fabricados, estando todos dentro dos padrões microbiológicos estabelecidos pela portaria $\mathrm{n}^{\circ} 359$ de 04 de novembro de 1997 do MAPA (BRASIL, 1997), indicando que as boas práticas de fabricação foram eficientes durante o processamento.

Diante dos resultados apresentados, as formulações T1, T2 e T3 apresentaram teor reduzido de lactose. Para dar sequência ao estudo e realizar a análise sensorial, foi escolhida para este teste a formulação $\mathrm{T} 1$, por necessitar menor concentração de enzima no processo de hidrólise.

A Tabela 5 apresenta as médias entre as notas obtidas para cada atributo analisado. Observa-se que os valores médios para os atributos variaram de 7 a 8 , ou seja, os julgadores classificaram o requeijão sem lactose entre "gostei moderadamente" e "gostei muito". Além disso, a intenção de compra ficou entre 4 e 5 , "possivelmente compraria" e "certamente compraria", respectivamente.

Tabela 4 - Resultados das contagens de coliformes a $30^{\circ} \mathrm{C}$ e $45^{\circ} \mathrm{C}$ e Staphylococcus Coagulase Positiva nos requeijões fabricados

\begin{tabular}{ccc}
\hline Teste & $\begin{array}{c}\text { Coliformes a } \\
30{ }^{\circ} \mathrm{C} \mathrm{e} 45^{\circ} \mathrm{C}(\mathrm{NMP} / \mathrm{mL})\end{array}$ & $\begin{array}{c}\text { Staphylococcus Coagulase Positiva } \\
(\mathrm{UFC} / \mathrm{mL})\end{array}$ \\
\hline $\mathrm{T} 1$ & $<3,0$ & $<1,0 \times 10^{1}$ \\
$\mathrm{~T} 2$ & $<3,0$ & $<1,0 \times 10^{1}$ \\
$\mathrm{~T} 3$ & $<3,0$ & $<1,0 \times 10^{1}$ \\
Controle & $<3,0$ & $<1,0 \times 10^{1}$ \\
\hline
\end{tabular}

Tabela 5 - Médias das notas obtidas na avaliação sensorial

\begin{tabular}{llllllc}
\hline \multicolumn{1}{c}{ Amostra } & Cor & Odor & Sabor & Textura & $\begin{array}{c}\text { Avaliação } \\
\text { Global }\end{array}$ & $\begin{array}{c}\text { Intenção de } \\
\text { compra }\end{array}$ \\
\hline $\begin{array}{l}\text { Formulação } \\
\text { sem lactose (T1) }\end{array}$ & $8,18^{\mathrm{a}}$ & $8,02^{\mathrm{a}}$ & $8,13^{\mathrm{a}}$ & $7,89^{\mathrm{a}}$ & $8,19^{\mathrm{a}}$ & $4,49^{\mathrm{a}}$ \\
\hline $\begin{array}{l}\text { Formulação } \\
\text { Padrão }\end{array}$ & $8,16^{\mathrm{a}}$ & $7,96^{\mathrm{a}}$ & $8,05^{\mathrm{a}}$ & $8,02^{\mathrm{a}}$ & $8,11^{\mathrm{a}}$ & $4,4^{\mathrm{a}}$ \\
\hline
\end{tabular}


Para todos os atributos avaliados na análise sensorial, não houve diferenças significativas ao nível de significância de 5\%, indicando que a formulação de requeijão sem lactose desenvolvida ficou semelhante sensorialmente ao requeijão cremoso tradicional comercial. Esse resultado demonstra que o processo de hidrólise realizado no estudo não alterou as características sensoriais e visuais que o consumidor está habituado a encontrar em requeijões. Confirma também que a concentração da enzima utilizada, além de se mostrar eficaz na hidrólise da lactose, não alterou a estrutura padrão do requeijão e não deixou sabor residual no produto final.

\section{CONCLUSÕES}

O requeijão sem lactose desenvolvido obteve uma boa aceitabilidade perante os consumidores, não havendo diferença significativa a $5 \%$ de probabilidade entre as duas formulações para os atributos avaliados, indicando que a enzima adicionada à formulação não exerceu efeito significativo nas características sensoriais do produto.

As características físico-químicas e microbiológicas do requeijão sem lactose estão de acordo com a legislação, portanto, a adição da enzima lactase não alterou tais características, garantindo um produto de baixo custo industrial e seguro para o consumo por pessoas intolerantes a lactose.

\section{REFERÊNCIAS}

ALMEIDA, K. de N. et al. Hidrólise Enzimática da Lactose de Permeado de Soro. Revista Instituto Cândido Tostes, vol. 70, n. 2, p. 55-63, 2015.

AGÊNCIA NACIONAL DE VIGILÂNCIA SANITÁRIA (ANVISA). Portaria n ${ }^{\circ} 29$, de 13 de janeiro de 1998. Aprova o Regulamento Técnico para Fixação de Identidade e Qualidade de Alimentos para Fins Especiais. Disponível em: <http://portal. anvisa.gov.br/documents/33916/388729/ PORTARIA_29_1998.pdf/e7a81013-459c49f6-a79e-f1a18f7b71cb>. Acesso em: 10 nov. 2016.

ARIAS, F. A. et al. The management of Lactose intolerance among primary care physicians and its correlation with management by gastroenterologists: the SEPDSEMG National Survey. Revista Española de Enfermedades Digestivas, vol. 107, n. 9, p. 554-558, 2015.

BRAGA, A. R. C. Obtenção e caracterização da enzima $\beta$-galactosidase submetida a diferentes processos: purificação, imobilização e altas pressões. 2012. 135 p. Tese (Doutorado em Engenharia e Ciência de Alimentos) - Universidade Federal do Rio Grande, Rio Grande, 2012.

BOSI, M. G. Desenvolvimento de processo de fabricação de requeijão light e de requeijão sem adição de gordura com fibra alimentar. 2008.284 p. Tese (Doutorado em Engenharia e Ciência de Alimentos) - Universidade Estadual de Campinas, Campinas, 2008.

BRASIL. Ministério da Agricultura e do Abastecimento. Departamento de Inspeção de Produtos de Origem Animal. Portaria no 359 de 04 de setembro de 1997. Regulamento Técnico para Fixação de Identidade e Qualidade do Requeijão Cremoso ou Requesón. Diário Oficial da República Federativa do Brasil. Brasília, 08 set. 1997. Seção 1, p. 19690.

BRASIL. Ministério da Agricultura, Pecuária e Abastecimento. Instrução Normativa $n^{\circ}$ 68, de 12 de dezembro de 2006. Oficializa os métodos analíticos oficiais físico-químicos, para controle de leite e produtos lácteos. 
Diário Oficial da República Federativa do Brasil, Brasília, 14 dez. 2006. Seção 1, p. 8.

BRASIL. Ministério da Agricultura, Pecuária e Abastecimento. Instrução Normativa $\mathrm{n}^{\mathrm{o}}$ 62, de 26 de agosto de 2003. Aprova os Métodos Analíticos Oficiais para Análises Microbiológicas para Controle de Produtos de Origem Animal e Água. Diário Oficial da República Federativa do Brasil, 18 de set. de 2003, seção I, p. 14.

\section{CARMINATTI, C. A. Ensaios de Hidrólise} Enzimática da Lactose em Reator a Membrana Utilizando Beta-Galactosidase Kluyveromyces lactis. 2001. 79 p. Dissertação (Mestrado em Engenharia Química) - Universidade Federal de Santa Catarina, Florianópolis, 2001.

DRUNKLER, D. A. Produção de Requeijão Cremoso Simbiótico. 2009.180 p. Tese (Doutorado em Tecnologia de Alimentos) - Universidade Federal do Paraná, Curitiba, 2009.

ENDRES, C. M. Produção de xarope hidrolisado de lactose do permeado de soro de leite e aplicação em bebida láctea fermentada. 2016. Dissertação (Mestrado em Ciência e Tecnologia de Alimentos), Universidade de Passo Fundo, Rio Grande, p. 91, 2016 .

FAEDO, R. et al. Obtenção de leite com baixo teor de lactose por processos de separação por membranas associados à hidrólise enzimática. Revista CIATEC - UPF, v. 3, p. 44-54, 2013.

FISCHER, J. Hidrólise de Lactose por $\beta$-galactosidase de Aspergillusoryzae Imo- bilizada em Reator de Leito Fixo. 2010. 137 p. Dissertação (Mestrado em Engenharia Química) - Universidade Federal de Uberlândia, Uberlândia, 2010.

MATTANNA, P. Desenvolvimento de Requeijão Cremoso com Baixo Teor de Lactose Produzido por Acidificação Direta e Coagulação Enzimática. 2001. 93 p. Dissertação (Mestrado em Ciencia e Tecnologia de Alimentos) - Universidade Federal de Santa Maria, Santa Maria, 2011.

PARRA P. et al. Análisis de test de aire espirado em niños com sospecha de intolerancia a la lactosa. Revista Chilena de Pediatría, vol. 86, n. 2, pág. 80-85, 2015.

SANTOS, F. F. P. et al. Intolerância à lactose e as consequências no metabolismo do cálcio. Revista Interfaces: Saúde, Humanas e Tecnologia, ano 2, v. 2, 2014.

TREVISAN, A. P. Influência de diferentes concentrações de enzima lactase e temperaturas sobre a hidrólise da lactose em leite pasteurizado. 2008. 60 p. Dissertação (Mestrado em Ciencia e Tecnologia de Alimentos) - Universidade Federal de Santa Maria, Santa Maria, 2008.

VAN DENDER, A. G. F. Requeijão Cremoso e Outros Queijos Fundidos: Tecnologia de Fabricação, Controle do Processo e Aspectos do Mercado. São Paulo: Fonte Comunicações e Editora LTDA: 2014. 447 p.

VIEIRA, M. C. et al. Análise de Viabilidade Econômica da Produção de Formulações de Requeijão Cremoso sem Adição de Gordura e com Teor Reduzido de Sódio. Informações Econômicas, v. 44, n. 3, São Paulo, 2014. 